\title{
Paroxetine Augments while Naloxone Abolishes the Analgesic Effect of Paracetamol in Acute Nociceptive Pain in Mice
}

\author{
Mohammad Raafat Abdalla*, Waleed Al Malki, Muhammad Ahmed \\ Department of Pharmacology and Toxicology, Faculty of Pharmacy, Umm Al-Qura University, Makkah, KSA. \\ Email: *raafatabdalla@hotmail.com \\ Received May $12^{\text {th }}$, 2013; revised June $15^{\text {th }}, 2013$; accepted June 25 ${ }^{\text {th }}, 2013$ \\ Copyright (C) 2013 Mohammad Raafat Abdalla et al. This is an open access article distributed under the Creative Commons Attribution Li- \\ cense, which permits unrestricted use, distribution, and reproduction in any medium, provided the original work is properly cited.
}

\begin{abstract}
The mechanism(s) of analgesic action of paracetamol (acetaminophen; N-acetyl-p-aminophenol) remains controversial. Previous studies on rats suggested that the antinociceptive action of paracetamol might involve the central descending inhibitory pain pathways recruiting both a serotoninergic and an opioidergic system. This study explores this issue in mice using paroxetine, the most potent selective serotonin re-uptake inhibitor, and the nonselective opioid pure antagonist naloxone. Animals were divided into two main groups for two separate experiments, each subdivided into 3 subgroups. In both experiments; the first group served as control, the second group received paracetamol ( $200 \mathrm{mg} / \mathrm{kg}$, i.p). In one experiment, the third group received paroxetine $(20 \mathrm{mg} / \mathrm{kg}$ p.o for 7 days) before paracetamol. In the other experiment, animals of the third group were pretreated with naloxone ( $5 \mathrm{mg} / \mathrm{kg}$, i.p) $30 \mathrm{~min}$ before paracetamol. The antinociceptive effect of paracetamol was tested using the hot plate test. Paracetamol displayed a significant antinociceptive activity that was augmented by pretreatment with paroxetine as was shown by maintenance of its effect beyond that shown by paracetamol alone. On the other hand, pretreatment with naloxone abolished paracetamol's antinociceptive activity in the hot-plate test. These results extended the previous observation in rats that the antinociceptive effect of paracetamol involved activation of a central descending pain inhibitory pathway with serotonin and opioidergic peptides being potential mediators recruited.
\end{abstract}

Keywords: Paracetamol; Paroxetine; Naloxone; Mice

\section{Introduction}

More than 100 years after its synthesis, the mechanism of analgesic action of paracetamol (acetaminophen; N-acetyl-p-aminophenol) remains controversial. Postulated mechanisms [1,2], including inhibition of cyclooxygenase isozymes, have been inadequate [3]. Its inhibitory activity on the synthesis of prostaglandin is more evident on cyclo-oxygenase 1 than on cyclooxygenase 2 [4], both peripherally and within the CNS, even though the exact antinociceptive mechanism of action of this drug is still not completely clear [5]. Its biochemical properties, such as its weak inhibitory activity on the synthesis of peripheral prostaglandins, its low plasma-protein binding, its liposolubility and its ability to cross the blood-brain barrier suggest a central activity, which has been reported in several studies both in animals [6] and in humans [7]. It

${ }^{*}$ Corresponding author. has been postulated that this central effect might be linked to the ability of paracetamol to inhibit central cyclo-oxygenase [2,5]. On the other hand, it has been demonstrated that tissue cyclooxygenase in rat brain homogenates is not inhibited in doses of paracetamol up to $100 \mathrm{mg} / \mathrm{kg}$ [8]. Thus, the inhibition of cyclo-oxygenase may not be solely responsible for the central analgesic effect of non steroidal anti-inflammatory drugs (NSAIDs) [9].

There is evidence to suggest that the serotonergic system may play a role in the antinociceptive mechanism of NSAIDs [10] and of paracetamol. There was considerable evidence supporting a role for 5-hydroxytryptamine (5-HT) in the modulation of nociceptive thresholds. Studies have shown that 5-HT plays an important role in the descending inhibitory pathway of pain transmission from brainstem to the spinal cord. Descending pain pathways originate in brainstem nuclei, the hypo- 
thalamus and the cortex and interact with afferent fibers, interneurons and projecting neurons in the dorsal horn of the spinal cord. They are multiple and their stimulation leads to inhibitory effects in most studies [11-13]. The neurotransmitters involved in these descending controls are serotonin, noradrenalin, dopamine and opioids [14]. 5-Hydroxy-tryptamine, applied iontophoretically to dorsal horn neurons does reduce the nociceptive responses of these neurons. [15] showed that the $5-\mathrm{HT}_{3}$ receptor antagonist, tropisetron, injected intrathecally, abolished the antinociceptive effect of paracetamol in an inflammatory pain model in rats. Most of the authors reported that $5-\mathrm{HT}_{3}$-receptor activation had an antinociceptive action [16-19], while few showed an involvement of $5-\mathrm{HT}_{2}$ receptor subtype [20] or $5-\mathrm{HT}_{1}$ [21].

It has been also proposed that other neurotransmitter systems, including opioidergic pathways, may be involved in the central analgesic effect of this class of drugs [22]. Raffa and co-workers [23] have discovered that the analgesic effect of acetaminophen involves recruitment of endogenous opioid pathways that lead to antinociceptive spinal-supraspinal "self-synergy". They also demonstrated a synergistic enhancement of acetaminophen's antinociceptive action by spinal administration of phentolamine [24], implicating an interaction between descending endogenous opioid pathways and spinal sites. On the other hand, a recent clinical study on human volunteers that naloxone did not inhibit paracetamol antinociception, suggesting no significant implication of the opioid system in paracetamol mechanism of action [25].

The study of the impact of modulating the serotonergic and opioidergic systems on the analgesic activity of paracetamol, therefore, might throw some light on the complex antinociceptive activity of this widely used drug. Accordingly, we decided to conduct a study on both neurotransmitter systems, serotonergic and opioidergic, to gain further insight into the mechanism of the analgesic action of paracetamol.

The purpose of this study was twofold. Firstly, to evaluate the impact of enhancing the central serotoninergic neurotransmission by the most potent selective serotonin reuptake inhibitor, paroxetine [26,27], on the antinociceptive effect of paracetamol in the hotplate test, hence the clinically relevant potential drug interaction between therapeutic doses of both paracetamol and this selective serotonin reuptake inhibitor is highlighted. Secondly, to find out whether naloxone, the opiate recaptors pure antagonist, was able to modify or prevent the antinociceptive effect of paracetamol in the same analgesimetric test, thus ruling out the potential involvement of endogenous opioid polypeptides in mediating the analgesic effect of this widely used medicine.

\section{Materials and Methods}

\subsection{Animals}

Adult albino mice weighing 25 - 30 g of either sex were used in our study. They were purchased from the animal facility of the pharmacology department, College of Pharmacy, King Abdul-Aziz University. The animals were housed in cages kept under constant environmental and nutritional conditions throughout the period of investigation. They were allowed a free access to water and diet consisting of standard chow.

\subsection{Drugs}

Paracetamol was obtained from Sigma-Aldrich Company, USA. Paroxetine hydrochloride was obtained from GlaxoSmithKline Company. Naloxone $\mathrm{HCl}$ was obtained from Hikma Pharmaceuticals, Amman, Jordan. Drugs were freshly prepared in aqueous solution in a concentration adjusted so that the volume administered is $0.1 \mathrm{ml} / 10 \mathrm{~g}$ animal weight.

\subsection{Experimental Design and Treatment Protocol}

The animals were divided into two sets, dedicated each for a separate experiment. Each set was subdivided into three groups, consisting each of 10 mice.

\subsubsection{Paroxetine Experiment}

Animals in Group 1 (served as normal control) as well as Group 2 were orally administered normal saline, at the same volume of the drug, for one week. In Group 3, paroxetine was daily administered by oral gavage in a dose of $20 \mathrm{mg} / \mathrm{kg}$ [28] (Takeuchi et al., 2010) for one week. At the end of the experiment day (on Day 7), all the animals were subjected to the hotplate test to determine the baseline withdrawal latency (see below). Thereafter, animals in Group 1 were intraperitoneally (i.p) injected with normal saline, while in Group 2 and Group 3, animals were i.p injected with paracetamol (200 mg/kg) [29] one hour after receiving the last oral dose of normal saline or paroxetine. Exactly after $15 \mathrm{~min}$, the hotplate test was started as described below.

\subsubsection{Naloxone Experiment}

On the experiment day, all the animals were subjected to the hotplate test before receiving any treatment to determine the baseline withdrawal latency (see below). Thereafter, animals in Group 1 were i.p injected with normal saline and served as control, while in Group 2, animals were i.p injected with paracetamol (200 mg/kg). Animals in Group 3 where pretreated with naloxone ( $5 \mathrm{mg} / \mathrm{kg}$, i.p) [30] $30 \mathrm{~min}$ before paracetamol injection. Exactly $15 \mathrm{~min}$ 
after, the hotplate test was started.

\subsection{Hot-Plate Test}

The central antinociceptive activity of paracetamol was evaluated by using a modified hot plate test following the method of [31]. This test measures the complex response to an acute, noninflammatory, nociceptive input and can be considered a good model for studying central antinociceptive activity [32].

Animals were placed individually onto a hot plate with temperature fixed at $55^{\circ} \mathrm{C} \pm 0.5^{\circ} \mathrm{C}$ (Harvard Apparatus Ltd., Kent, UK). Exposure to heat was continued till the animal shows withdrawal response in the form of hind paw licking, shaking or lifting or jumped off. To minimize tissue damage, a cut-off time (removing from the plate) of 30 seconds was adopted. The withdrawal latency was defined as the time period between the moment when the animal was placed on the hot plate surface and the moment when the animal licked, shaked or lifted any of its hind paws or jumped off to avoid thermal pain. The baseline latency (pretreatment value) was determined just before paracetamol or saline injection. The withdrawal latency was again determined at 15, 30, 45, $60,75,90,105$ and 120 min after. The prolongation in the withdrawal latency was taken as an index for the antinociceptive effect of paracetamol.

\subsection{Data Analysis}

All values in this study are expressed as mean \pm standard error of the mean $(\mathrm{M} \pm \mathrm{SEM})$. Data were analyzed by one-way analysis of variance (ANOVA). When variation among groups was found significant, Tukey-Kramer multiple comparisons test was carried out to compare between groups. Differences were considered significant when $\mathrm{p}$ value was $<0.05$.

\section{Results}

\subsection{Effect of Paroxetine}

As shown in Figure 1, the normal (pretreatment) withdrawal latency of control mice was $13.25 \pm 0.62 \mathrm{sec}$. After saline injection, this value showed insignificant variation along the whole experimental period. After injection of paracetamol, the withdrawal latency was gradually and significantly prolonged, starting $15 \mathrm{~min}$ after injection, reaching a maximum of $26.63 \pm 0.86$ seconds after $90 \mathrm{~min}$. However, it started to decline back to reach $18.25 \pm 0.77 \mathrm{sec}$. at the end of the evaluation period (120 min).

In paroxetine-pretreated animals, the effect of paracetamol did not quantitatively differ from that in paracetamol-only treated group. However, at the time where its effect started to fade in the paracetamol-only treated group (105 min), the antinociceptive effect of paracetamol continued at the same level, achieving a value of $25.75 \pm 1.11 \mathrm{sec}$. at the end of the test period. It could be concluded that pretreatment with paroxetine potentiated the antinociceptive effect of paracetamol during the late phase of its action, leading to prolongation of its effect for at least $30 \mathrm{~min}$.

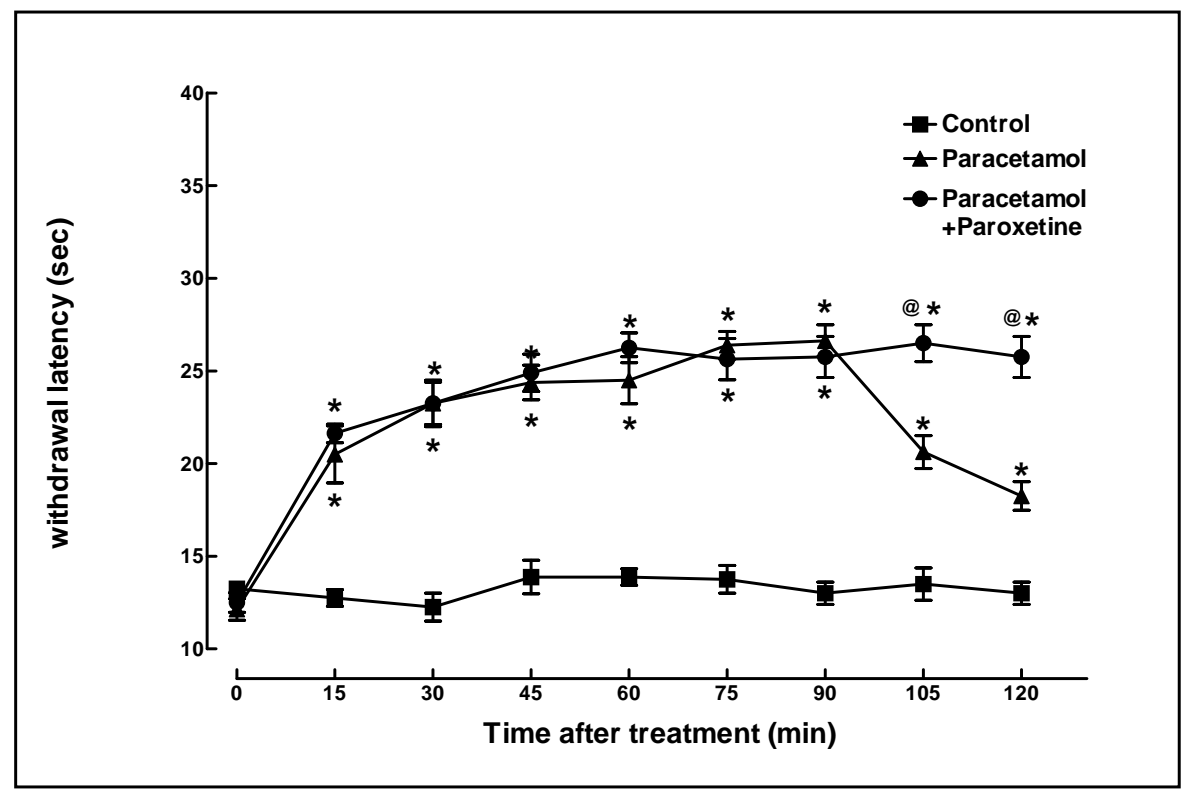

Figure 1. Antinociceptive effect of a single dose of paracetamol $(200 \mathrm{mg} / \mathrm{kg}$, i.p) in normal mice and in mice pretreated with paroxetine $(20 \mathrm{mg} / \mathrm{kg}$, p.o for 7 days). Values are represented as means \pm S.E. of 8 - 10 separate experiments. "Significantly different from respective control values at $\mathbf{p}<0.05$. ${ }^{\circledR}$ Significantly different from respective paracetamol values at $p<0.05$. 


\subsection{Effect of Naloxone}

As shown in Figure 2, the normal (pretreatment) withdrawal latency of control mice was $8.88 \pm 1.13$ sec. After saline injection, this value showed insignificant variation along the whole experimental period. After injection of paracetamol, the withdrawal latency was gradually and significantly prolonged, starting $30 \mathrm{~min}$ after injection, reaching a maximum of $23.13 \pm 0.7$ sec. after 75 min. However, it started to decline back to reach $10.88 \pm 1.37$ sec. at the end of the evaluation period (120 min).

In naloxone-pretreated animals; the effect of paracetamol was reversed such that no antinociceptive effect was observed at any of the evaluation time points.

\section{Discussion}

In the present investigation, the antinociceptive effect of paracetamol against thermal pain was evident shortly after i.p. injection, manifested as prolongation in the withdrawal latency 15 - 30 min after injection. This effect reached a maximum after 75 - 90 min, thereafter started to fade gradually. Paracetamol is often classified in the group of aspirin like [33] or NSAIDs-like drugs [34]. However, it does not share the same profile both in terms of therapeutic activities and side effects. This seems to be due, at least in part; to the inhibition of the synthesis of PGs [35]. These marked differences suggest that its mechanism of action may differ. In vitro, paracetamol weakly inhibits COX, compared to several NSAIDs [36]. Clinical experiments have shown that therapeutic doses of paracetamol failed to reduce 6-
keto-PGF1 $\alpha$ urinary excretion [37] or PGE2 synovial fluid levels $[38,39]$ also demonstrated that paracetamol weakly inhibits peripheral COX but has a more potent effect on the centrally located enzymes. This limited inhibition of COX, especially of peripheral COX, led several authors to propose a central mechanism of action of paracetamol $[19,40]$. Such a hypothesis is in line with the ability of paracetamol to cross the blood brain barrier both in rats [41] and humans [19], and with its efficacy maintained in animal pain models after central administration [16] and in models devoid of any inflammation and only sensitive to centrally acting drugs [42]. Some neurobiochemical hypotheses have been proposed for this centrally mediated effect since paracetamol reduces behavior induced by intrathecally injected substance $\mathrm{P}$ or N-methyl-D-aspartate (NMDA) [23]. Involvement of endogenous opioids [30,33] and of another variant of COX 1 (COX 3) located in the CNS as a crucial enzyme inhibited by the drug [43]. An inhibitory effect of paracetamol on a COX1 variant (COX3) has been described by Botting [44]. However, the author stated that this enzyme would be involved in the resolution of inflammation, i.e. in a late phase after carrageenan administration, which excluded the involvement of such a mechanism in the "rapid" antinociceptive effect of paracetamol observed here. Hence, systemically administered paracetamol acts differently from aspirin and NSAIDs and independently of peripheral PG synthesis and of any antiinflammatory effect.

There are already reports of the central actions of paracetamol in a variety of pain models $[22,33,45]$ or of

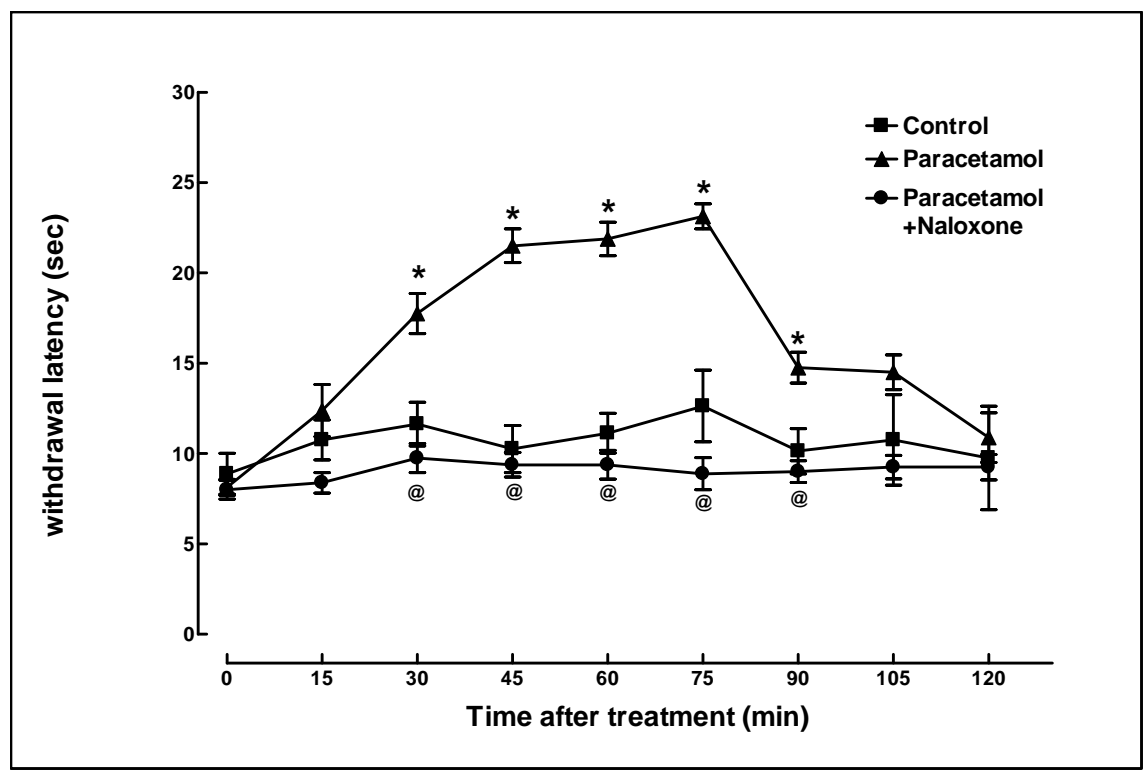

Figure 2. Antinociceptive effect of a single dose of paracetamol $(200 \mathrm{mg} / \mathrm{kg}$, i.p) in normal mice and in mice pretreated with naloxone ( $5 \mathrm{mg} / \mathrm{kg}$, i.p $30 \mathrm{~min}$ before). Values are represented as means \pm S.E. of 10 separate experiments. "Significantly different from respective control values at $\mathrm{p}<0.05$. ${ }^{\circledR}$ Significantly different from respective paracetamol values at $\mathrm{p}<0.05$. 
its actions at a spinal level $[16,40,46]$. These reports have also linked the actions of paracetamol to a descending 5 -HT pathway $[16,40,45]$. Control of analgesia is performed by the descending inhibitory pathways in the central nervous system. The key part of this descending system is the periaque-ductal grey area (PAG) which receives inputs from different brain regions and is assumed to be a gate in control of nociception, especially in the dorsal horn. PAG mainly stimulates the nucleus raphe magnus (NRM) and some fibers in the spinal cord, which form synaptic connections on dorsal horn interneurons. 5-HT is the major transmitter both at these synapses and the pathway from the NRM to the substantia gelatinosa of the dorsal horn ${ }^{25}$. Activation of this pathway inhibits transmission specifically in nociceptive pathways [47]. The 5-HT3 receptors located in the dorsal horn of the rat spinal cord have been shown to mediate an antinociceptive effect $[16,48]$ demonstrated a spinal antinociceptive action for paracetamol that was reversed by the $5-\mathrm{HT}_{3}$ receptor antagonist, tropisetron. The augmentation of the antinociceptive action of paracetamol in mice being treated with paroxetine observed in this study may further highlights the involvement of 5-HT in this action and gives further insight into this postulation. Several authors have demonstrated a serotoninergic involvement in the antinociceptive effect of paracetamol $[11,16,21$, 49-51].

Since the antidepressant mechanisms of SSRI drugs are attributed to an increase in the amount and action of serotonin in the synaptic gap due to its serotonin re-uptake inhibitory effect on the presynaptic site $[27,28]$, extension of this effect to the descending serotoninergic spinal pathways would be conceivable as a mechanism of potentiation and/or prolongation of the analgesic effect of paracetamol. Indeed, Duman and co-workers [31] demonstrated that the $5-\mathrm{HT}_{3}$ receptors antagonist, ondansetron inhibits the antinociceptive effect of paroxetine, while the $5-\mathrm{HT}_{2}$ receptors antagonist ketanserin could not. This finding suggests a contribution of $5-\mathrm{HT}_{3}$ receptors rather than $5-\mathrm{HT}_{2}$ types, to the antinociceptive action of paroxetine. In conclusion, both paracetamol and paroxetine antinociception implicate the descending inhibittory serotoninergic pathway in their effect, with $5-\mathrm{HT}_{3}$ subtype being the receptor involved. Our results, thus, would be compatible with a mechanistic scheme, which involved a central site of action of paracetamol, with algesia being devoid of a peripheral inflammatory component. The potential clinically relevant drug interaction between this widely used analgesic and SSRIs might warrant investigation on human volunteers.

In our study, the reversal of the antinociceptive action of paracetamol in mice being treated with naloxone supports the involvement of endogenous opioids in this ac- tion and gives further insight into this postulation. The results of the present study confirm that opioidergic system was engaged in the mechanism of paracetamol action. This observation is in agreement with results obtained by [51] who also noted that the antinociceptive effect of paracetamol was reversed by nonselective opioid receptor antagonist naloxone in the hot-plate test in rats. Some studies have indicated that some NSAIDs exert a central opioid receptor-mediated effect [52], although the exact mechanism has not been fully elucidated. Indeed, indirect action on opioid receptors with release of endorphins or enkephalins has already been proposed for diclofenac [53] and ketorolac [54]. On the other hand, our result is not in line with that of [26] who observed that naloxone did not inhibit paracetamol antinociception, in human volunteers, suggesting no significant implication of the opioid system in paracetamol mechanism of action. However, the authors attributed this apparent lack of effect to a matter of the power of their study, being carried out on only 12 healthy male volunteers.

Possible interaction of paracetamol with naloxone binding sites has been investigated. Competition experiments demonstrated that paracetamol, though with low affinity, competes for [3H] naloxone binding sites [33]. This indicated that paracetamol might behave like morphine regarding not only its analgesic effect but also its action on $\mu$-receptors. The authors suggested a dose-related effect in which paracetamol might bind directly to opioid recaptors only at high concentrations. It is, however, hard to believe that paracetamol acts directly on opioidergic receptors since Pelissier [11] were unable to demonstrate paracetamol affinity for these receptors in vitro. It may be, therefore, suggested that paracetamol activates opioidergic system indirectly via still unknown mechanism or mechanisms. In this regard, it has been suggested that paracetamol indirectly activate opiate receptors that in turn may increase 5-HT levels, at least in the cerebral cortex and in the pons, thus provoking an analgesic effect [46]. Indeed, in the mechanism of action of paracetamol, a 5-HT-mediated antinociception is of interest because central 5-HT activation potentiates the effect of opioids, as observed in rats [54] and humans [55]. On the other hand, it has been shown that naloxone blocks the increase in 5-HT levels in the brain induced by paracetamol [33]. These potentially regulatory and interactive mechanisms between 5-HT and opioid transmission in nociception are supported by the finding that the analgesic effect of paracetamol depends on an intact 5-HT neurotransmission and is antagonized by the opioid antagonist naloxone [33]. Noteworthy, morphine induces changes in the serotoninergic system similar to those obtained with paracetamol, which are also reversed by naloxone. 
Thus it may be hypothesized that paracetamol, in acting on opiate receptors, may release 5-HT that provokes an analgesic effect. This is supported by many findings which indicate that 5-HT takes part in the complex nociceptive pathways and plays a pivotal role in antinociception. In conclusion, these data provide further evidence for a central antinociceptive effect of PARA antagonized by naloxone, which suggests that this activity may involve the opioidergic pathways which in turn activate the serotonergic system.

\section{REFERENCES}

[1] J. S. Walker, "NSAID: An Update on Their Analgesic Effects," Clinical and Experimental Pharmacology and Physiology, Vol. 22, No. 11, 1995, pp. 855-860. doi:10.1111/j.1440-1681.1995.tb01950.x

[2] R. Björkman, "Central Antinociceptive Effects of Non-Steroidal Anti-Inflammatory Drugs and Paracetamol," Acta Anaesthesiologica Scandinavica, Vol. 39, Suppl. 103, 1995, pp. 2-44. doi:10.1111/j.1399-6576.1995.tb04249.x

[3] T. D. Warner, I. Vojnovic, F. Giuliano, R. Jiménez, D. Bishop-Bailey and J. A. Mitchell, "Cyclo-Oxygenases 1, 2, and 3 and the Production of Prostaglandin I2: Investigating the Activities of Acetaminophen and Cyclooxygenase-2-Selective Inhibitors in Rat Tissues," Journal of Pharmacology and Experimental Therapeutics, Vol. 310, No. 2, 2004, pp. 642-647. doi:10.1124/jpet.103.063875

[4] J. R. Vane and R. M. Botting, “A Better Understanding of Anti-Inflammatory Drugs Based on Isoforms of Cyclooxygenase (COX-1 and COX-2)," Advances in Prostaglandin, Thromboxane, and Leukotriene Research, Vol. 23, 1995, pp. 41-48.

[5] S. P. Clissold, "Paracetamol and Phenacetin," Drugs, Vol. 32, Suppl. 4, 1986, pp. 46-59.

[6] K. H. Carlsson, W. Monzel and I. Jurna, "Depression by Morphine and the Non-Opioid Analgesic Agents Metamizol (Dipyrone), Lysine Acetylate and Paracetamol, of Activity in Rat Thalamus Neurons Evoked by Electrical Stimulation of Nociceptive Afferents," Pain, Vol. 32, No. 3, 1988, pp. 313-326. doi:10.1016/0304-3959(88)90043-7

[7] C. A. N. Chen and C. R. Chapman, “Aspirin Analgesia Evaluated by Event Related Potentials in Man: Possible Central Action in Brain,” Experimental Brain Research, 39, No. 4, 1980, pp. 359-364. doi:10.1007/BF00239300

[8] M. S. Abdel-Alim, B. Sjoqvist and E. Anggard, "Inhibition of Prostaglandin Synthesis in Rat Brain," Acta Pharmacologica et Toxicologica, Vol. 43, No. 4, 1978, pp. 266-272. doi:10.1111/j.1600-0773.1978.tb02264.x

[9] A. B. Malberg and T. L. Yaks, “Antinociceptive Actions of Spinal Anti-Inflammatory Agents on the Formalin Test in the Rat," Journal of Pharmacology and Experimental Therapeutics, Vol. 263, No. 1, 1992, pp. 136-146.

[10] M. Sandrini, G. Vitale, M. Dondi and L. A. Pini, "Effects of Acetylsalicylic Acid on Serotonin Brain Receptor Sub- types,” General Pharmacology, Vol. 26, No. 4, 1995, pp. 737-741. doi:10.1016/0306-3623(94)00252-I

[11] J. C. Willer, A. Roby and D. Le Bars, "Psychophysical and Electrophysiological Approaches to the Pain-Relieving Effects of Heterotopic Nociceptive Stimuli," Brain, 107, No. 4, 1984, pp. 1095-1112. doi:10.1093/brain/107.4.1095

[12] D. D. Price and J. G. McHaffie, "Effects of Heterotopic Conditioning Stimuli on First and second Pain: A Psychophysical Evaluation in Humans,” Pain, Vol. 34, No. 3, 1988, pp. 245-252. doi:10.1016/0304-3959(88)90119-4

[13] J. D. Talbot, G. H. Duncan and M. C. Bushnell, "Effects of Diffuse Noxious Inhibitory Controls (DNICs) on the Sensory-Discriminative Dimension of Pain Perception," Pain, Vol. 36, No. 2, 1989, pp. 231-238. doi:10.1016/0304-3959(89)90028-6

[14] N. Julien and S. Marchand, "Endogenous Pain Inhibitory Systems Activated by Spatial Summation Are OpioidMediated,” Neuroscience Letters, Vol. 401, No. 3, 2006, pp. 256-260. doi:10.1016/j.neulet.2006.03.032

[15] A. Alloui, C. Chassaing, J. Schimidt, D. Ardidi, C. Dubray and A. Cloarec, "Paracetamol Exerts a Spinal, Tropisetron-Reversible, Antinociceptive Effect in an Inflammatory Pain Model in Rats," European Journal of Pharmacology, Vol. 443, No. 1-3, 2002, pp. 71-77. doi:10.1016/S0014-2999(02)01578-9

[16] S. R. Glaum, H. K. Proudfit and E. G. Anderson, "Reversal of the Antinociceptive Effects of Intrathecally Administered Serotonin in the Rat by a Selective 5-HT3 Receptor Antagonist,” Neuroscience Letters, Vol. 95, No. 1-3, 1988, pp. 313-317. doi:10.1016/0304-3940(88)90677-5

[17] S. R. Glaum, H. K. Proudfit and E. G. Anderson, "5-HT3 Receptors Modulate Spinal Nociceptive Reflexes,” Brain Research, Vol. 510, No. 1, 1990, pp. 12-16. doi:10.1016/0006-8993(90)90721-M

[18] B. Bannwarth, P. Netter, F. Lapicque, P. Gillet, P. Pére, E. J. Boccard and A. Eschalier, "Paracetamol Exerts a Spinal Antinociceptive Effect Involving an Indirect Interaction with 5-Hydroxytryptamine 3 Receptors: In Vivo and In Vitro Evidence," Journal of Pharmacology and Experimental Therapeutics, Vol. 278, No. 1, 1996, pp. 8-14.

[19] L. Bardin, J. Schmidt, A. Alloui and A. Eschalier, "Effect of Intrathecal Administration of Serotonin in Chronic Pain Models in Rats,” European Journal of Pharmacology, Vol. 409, No. 1, 2000, pp. 37-43. doi:10.1016/S0014-2999(00)00796-2

[20] A. Srikiatkhachorn, N. Trasu and P. Govitrapong, “Acetaminophen Induced Antinociception via Central 5-HT 2A Receptors," Neurochemistry International, Vol. 34, No. 6, 1999, pp. 491-498. doi:10.1016/S0197-0186(99)00023-6

[21] G. G. Graham and K. F. Scott, "Mechanism of Action of Paracetamol," American Journal of Therapeutics, Vol. 12, No. 1, 2005, pp. 46-55. doi:10.1097/00045391-200501000-00008

[22] R. Björkman, "Central Antinociceptive Effects of Non-St eroidal Anti-Inflammatory Drugs and Paracetamol,” Acta Anaesthesiologica Scandinavica, Vol. 39, Suppl. 103, 1995, 
pp. 2-44. doi:10.1111/j.1399-6576.1995.tb04249.x

[23] R. B. Raffa, J. R. Stone and D. J. Tallarida, "Discovery of 'Self-Synergistic' Spinal/Supraspinal Antinociception Produced by Acetaminophen (Paracetamol)," Journal of Pharmacology and Experimental Therapeutics, Vol. 295, No. 1, 2000, pp. 291-294.

[24] R. B. Raffa, J. R. Stone and D. J. Tallarida, “Unexpected and Pronounced Anti-Nociceptive Synergy between Spinal Acetaminophen (Paracetamol) and Phentolamine," European Journal of Pharmacology, Vol. 412, No. 2, 2001, pp. R1-R2. doi:10.1016/S0014-2999(01)00722-1

[25] G. Pickering, F. Moustafa, S. Desbrandes, J. M. Cardot, D. Roux and C. Dubray, "Paracetamol and Opioid Pathways: A Pilot Randomized Clinical Trial,” Fundamental \& Clinical Pharmacology, Vol. 27, No. 3, 2013, pp. 339345.

[26] E. Richelson, "Where Are All the Novel Antidepressants?” Current Opinion in Investigational Drugs, Vol. 2, No. 2, 2001, pp. 256-258.

[27] M. Bourin, A. J. Fiocco and F. Clenet, "How Valuable Are Animal Models in Defining Antidepressant Activity?” Human Psychopharmacology, Vol. 16, No. 1, 2001, pp. 9-21. doi:10.1002/hup.178

[28] T. Takeuchi, T. Owa, T. Nishino and C. Kamei, “Assessing Anxiolytic-Like Effects of Selective Serotonin Reuptake Inhibitors and Serotonin-Noradrenaline Reuptake Inhibitors Using the Elevated plus Maze in Mice,” Methods \& Findings in Experimental \& Clinical Pharmacology, Vol. 32, No. 2, 2010, pp. 113-121.

[29] R. M. Rezende, D. S. França, G. B. Menezes, W. G. dos Rei, Y. S. Bakhle and J. N. Francischi, "Different Mechanisms Underlie the Analgesic Actions of Paracetamol and Dipyrone in a Rat Model of Inflammatory Pain,” British Journal of Pharmacology, Vol. 153, No. 4, 2008, pp. 760-768. doi:10.1038/sj.bjp.0707630

[30] N. E. Duman, M. Kesim, M. Kadioglu, E. Yaris, N. I. Kalyoncu and N. Erciyes, "Possible Involvement of Opioidergic and Serotonergic Mechanisms in Antinociceptive Effect of Paroxetine in Acute Pain," Journal of Pharmacological Sciences, Vol. 94, No. 2, 2004, pp. 161-165. doi:10.1254/jphs.94.161

[31] T. R. Lavich, R. S. Cordeiro, P. M. Silva and M. A. Martins, "A Novel Hot-Plate Test Sensitive to Hyperalgesic Stimuli and Non-Opioid Analgesics,” Brazilian Journal of Medical and Biological Research, Vol. 38, No. 3, 2005, pp. 45-51. doi:10.1590/S0100-879X2005000300016

[32] L. A. Pini, G. Vitale, A. Ottani and M. Sandrini, "Naloxone-Reversible Anti-Nociception by Paracetamol in the Rat," Journal of Pharmacology and Experimental Therapeutics, Vol. 280, No. 2, 1997, pp. 934-940.

[33] S. H. Ferreira, "Prostaglandins, Aspirin like Drugs and Analgesia,” Nature, Vol. 240, 1972, pp. 200-203.

[34] P. A. Insel, "Analgesic-Antipyretic and Anti-Inflammatory Agents and Drugs Employed in the Treatment of Gout,” In: J. G. Hardman, L. E. Limbird, P. B. Molinoff, R. W. Ruddon and A. Goodman Gilman, Eds., Goodman and Gilman's the Pharmacological Basis of Therapeutics, 9th Edition, McGraw-Hill, New York, 1996, pp. 617-
657.

[35] J. A. Mitchell, P. Akarasereenont, C. Thiemermann, R. J. Flower and J. R. Vane, "Selectivity of Non Steroidal Anti-Inflammatory Drugs as Inhibitors of Constitutive and Inducible Cyclooxygenase," Proceedings of the $\mathrm{Na}$ tional Academy of Sciences, Vol. 90, No. 24, 1994, pp. 11693-11697. doi:10.1073/pnas.90.24.11693

[36] E. Seppala, O. Laitinen and H. Vapaaltalo, "Comparative Effects of Acetyl-Salicylic Acid, Indomethacin and Paracetamol on Metabolites of Arachidonic Acid in Plasma and Urine in Man,” International Journal of Clinical Pharmacology Research, Vol. 4, No. 3, 1983, pp. 265269.

[37] H. Bippi and Jc. Frohich, "Effects of Acetylsalicylic Acid and Paracetamol Alone and in Combination on Prostanoid Synthesis in Man," British Journal of Clinical Pharmacology, Vol. 29, No. 3, 1990, pp. 305-310. doi:10.1111/j.1365-2125.1990.tb03640.x

[38] J. R. Vane, "Inhibition of Prostaglandin Synthesis as a Mechanism of Action for Aspirin like Drugs," Nature New Biology, Vol. 231, No. 25, 1971, pp. 232-235.

[39] J. Bonnefont, E. Chapuy, E. Clottes, A. Alloui and A. Eschalier, "Spinal 5-HT1A Receptors Differentially Influence Nociceptive Processing According to the Nature of the Noxious Stimulus in Rats: Effect of WAY-100635 on the Antinociceptive Activities of Paracetamol, Venlafaxine and 5-HT,” Pain, Vol. 114, No. 3, 2005, pp. $482-$ 490. doi:10.1016/j.pain.2005.01.019

[40] A. Cloarec, "Effect of Acetaminophen on Monoaminergic System in the Rat Central Nervous System," NaunynSchmiedeberg's Archives of Pharmacology, Vol. 364, No. 6, 2001, pp. 534-537. doi:10.1007/s002100100484

[41] K. H. Carlsson and I. Jurna, "Central Analgesic Effects of Paracetamol Manifested by Depression of Nociceptive Activity in Thalamic Neurons of the Rat," Neuroscience Letters, Vol. 77, No. 3, 1987, pp. 339-343. doi:10.1016/0304-3940(87)90524-6

[42] R. Botting and S. S. Ayoub, "COX-3 and the Mechanism of Action of Acetaminophen/Paracetamol," Prostaglandins, Leukotrienes and Essential Fatty Acids, Vol. 72, No. 2, 2005, pp. 85-87. doi:10.1016/j.plefa.2004.10.005

[43] R. M. Botting, "Mechanism of Action of Paracetamol: Is There a Cyclooxygenase 3?” Clinical Infectious Diseases, Vol. 31, Suppl. 5, 2000, pp. S202-S210.

[44] J. Bonnefont, J. P. Courade, A. Alloui and A. Eschalier, "Antinociceptive Mechanism of Action of Paracetamol," Drugs, Vol. 63, No. 2, 2003, pp. 1-4. doi:10.2165/00003495-200363992-00002

[45] R. B. Raffa, E. A. Walker and S. N. Sterious, "Opioid Receptors and Paracetamol (Acetaminophen),” European Journal of Pharmacology, Vol. 503, No. 1, 2004, pp. 209-210. doi:10.1016/j.ejphar.2004.08.055

[46] H. L. Fields and A. I. Basbaum, "Central Nervous System Mechanisms of Pain Modulation,” In: P. D. Wall and R. Melzack, Eds. Textbook of Pain, 3rd Edition, Churchill Livingstone, Edinburgh, 1994, pp. 243-257. 
[47] M. Sasaki, K. Ishizaki, H. Obata and F. Goto, "Effects of 5-HT2 and 5-HT3 Receptors on the Modulation of Nociceptive Transmission in Rat Spinal Cord According to the Formalin Test," European Journal of Pharmacology, Vol. 424, No. 1, 2001, pp. 45-52. doi:10.1016/S0014-2999(01)01117-7

[48] A. Tjolsen, A. Lund and K. Hole, “Antinociceptive Effect of Paracetamol in Rats Is Partly Dependent on Spinal Serotonergic Systems,” European Journal of Pharmacology, Vol. 193, No. 2, 1991, pp. 193-201. doi:10.1016/0014-2999(91)90036-P

[49] L. A. Pini, M. Sandrini and G. Vitale, “The Antinociceptive Action of Paracetamol Is Associated with Changes in the Serotoninergic System in the Rat Brain,” European Journal of Pharmacology, Vol. 308, No. 1, 1996, pp. 3140. doi:10.1016/0014-2999(96)00261-0

[50] M. Sandrini, G. Vitale, A. Ottani and L. A. Pini, "The Potentiation of Analgesic Activity of Paracetamol plus Morphine Involves the Serotoninergic System in Rat Brain,” Inflammation Research, Vol. 48, No. 3, 1999, pp. 120-127. doi:10.1007/s000110050434
[51] H. Vanegas and V. Tortorici, "Opioidergic Effects of Nonopioid Analgesics on the Central Nervous System," Cellular and Molecular Neurobiology, Vol. 22, No. 5-6, 2002, pp. 655-661. doi:10.1023/A:1021896622089

[52] P. Sacerdote, G. Moza, P. Mantegazza and A. E. Panerai, "Diclofenac and Pirprofen Modify Pituitary and Hypothalamic Beta-Endorphin Concentrations," Pharmacological Research Communications, Vol. 17, No. 8, 1983, pp. 679-684. doi:10.1016/0031-6989(85)90085-2

[53] M. Baraldi, R. Poggioli, M. Santi, A. V. Verogoni and A. Bertolini, "Antidepressantsand Opiates Interactions: Pharmacological and Biochemical Evidences,” Pharmacological Research Communications, Vol. 15, No. 9, 1983, pp. 843-857. doi:10.1016/S0031-6989(83)80092-7

[54] K. C. Bentley and T. W. Head, "The Additive Analgesic Efficacy of Acetaminophen,1000 mg, and Codeine, 60 mg, in Dental Pain," Clinical Pharmacology \& Therapeutics, Vol. 42, No. 6, 1987, pp. 634-640. doi:10.1038/clpt.1987.211

[55] R. Malmgren, "The Central Serotoninergic System," Cephalalgia, Vol. 10, 1990, pp. 199-204. doi:10.1046/j.1468-2982.1990.1004204.x 